\title{
BICORNUATE UTERUS WITH CERVICAL ATRESIA AND VAGINAL AGENESIS ASSOCIATED WITH OVARIAN ENDOMETRIOSIS - A CASE REPORT
}

Alpana Singh ${ }^{1}$, Vijaylakshmi A.R ${ }^{2}$.

1. Assistant Professor, Department of Obstetrics and Gynecology, Malla Reddy Institute of medical sciences.

2. Professor \& Head of the Department, Department of Obstetrics and Gynecology, Malla Reddy Institute of medical sciences.

\section{CORRESPONDING AUTHOR}

Alpana Singh,

Department of Obstetrics and Gynecology,

Malla Reddy Institute of Medical Sciences,

Suraram Main Road, GHMC, Quthabullapur, Jeedimetla,

Hyderabad- 500055, Andhra Pradesh.

Email- dralpanasingh21@gmail.com

\section{HOW TO CITE THIS ARTICLE:}

Alpana Singh, Vijaylakshmi A.R. "Bicornuate Uterus with Cervical Atresia and Vaginal Agenesis Associated with Ovarian Endometriosis". Journal of Evolution of Medical and Dental Sciences 2013; Vol2, Issue 24, June 17; Page: 4287-4290.

ABSTRACT: Vaginal agenesis combined with a functional uterus is a rare type of Mullerian duct anomaly. Only $7-8 \%$ of patients with vaginal agenesis have a functional uterus. Women born with vaginal agenesis, cervical atresia combined with a functioning endometrium typically present with hematometra, disabling pelvic pain and progressively worsening endometriosis. Almost all need an abdominal hysterectomy for relief. We report a case of severe endometriosis in a 29 years old woman having a bicornuate uterus with cervical atresia and vaginal agenesis.

KEYWORDS: mullerian duct, cervical atresia, vaginal agenesis, endometriosis.

INTRODUCTION: Developmental anomalies of the mullerian duct system represent some of the most fascinating disorders that obstetricians and gynecologists encounter. The mullerian ducts are the primordial anlage of the female reproductive tract. They differentiate to form the fallopian tubes, uterus, cervix and the superior aspect of the vagina. A wide variety of malformations can occur when this system is disrupted. Vaginal agenesis combined with a functional uterus is a rare condition with a reported incidence of 1 in 4000 to 1 in 10500 female births (Griffin et al., 1976)(1). Only $7-8 \%$ of patients with vaginal agenesis have a functional uterus (2). Most mullerian duct anomalies are associated with functioning ovaries and age-appropriate external genitalia. Women born with vaginal agenesis and cervical atresia combined with functioning endometrium typically present with hematometra, disabling pelvic pain, and progressively worsening endometriosis. Here we report a case of vaginal agenesis combined with a functional bicornuate uterus with cervical atresia presenting with severe endometriosis. This case has lateral fusion defect in association with congenital atresia of uterine cervix and vaginal agenesis. This unusual case combined two development anomalies of the mullerian duct. 
CASE REPORT: A 29 years old woman presented to the gynaec OPD with complains of primary amenorrhoea and intermittent pain in the lower abdomen since 15 years. Pain was confined to lower abdomen, cyclical coming at monthly interval, radiating to back and both the legs and progressively increasing in intensity. She had vaginoplasty done 10 years back for non-canalized vagina (just before marriage). On examination her general condition was satisfactory, she had normal pattern of sexual hair growth, breast development and external genitalia. On per abdomen examination mild tenderness was noted in lower abdomen, more in right iliac fossa. On bimanual examination, vagina was approximately 2.5 inches long, cervix was rudimentary uterus was anteverted and small in size. Through right fornix a cystic mass of size $6 \mathrm{~cm} \mathrm{x} 6 \mathrm{~cm}$ could be felt. Ultrasound and computed tomography was done. CT revealed a hypoplastic bicornuate uterus of size $4.8 \mathrm{~cm} \times 3.0 \mathrm{~cm} \times 2.7 \mathrm{~cm}$, endometrial thickness of $5 \mathrm{~mm}$ and right ovarian cyst of size $6.1 \mathrm{~cm} \mathrm{x}$ $5.1 \mathrm{~cm}$ containing internal echoes and septations suggesting a hemorrhagic ovarian cyst. After base line investigations, patient underwent a laparotomy. Per-operatively uterus was bicornuate with small cervix. Right side ovary was adhered to posterior surface of uterus, enlarged $7 \mathrm{~cm} x 7 \mathrm{~cm}$, cystic, containing dark chocolate coloured fluid suggestive of endometrioma [Fig 1]. Left side ovary was also enlarged having a small $3 \mathrm{~cm} \times 3 \mathrm{~cm}$ of cyst containing old blood. Multiple endometriotic spots were present in pouch of Douglas. Total abdominal hysterectomy with right salpingooophorectomy and left ovarian cystectomy was done. Cut section of uterus showed two endometrial cavities with small non-canalized cervix [Figure 2]. Post operative period was uneventful. Histopathological examination confirmed the secretory phase of endometrium with ovarian endometriosis.

DISCUSSION: The true incidence and prevalence of mullerian duct anomalies are difficult to assess. Examination of different patient populations, no standardized classification system and differences in diagnostic data acquisition has resulted in widely disparate estimates. Most authors report incidences of $0.1-3.5 \%(3,4,5)$. In 2001, Grimbizis and colleagues reported that the mean incidence of uterine malformations was $4.3 \%$ for the general population and/or for fertile women (6). A bicornuate uterus consists of two symmetric cornua that are fused caudally, with communication of the endometrial cavities - most often at the level of the uterine isthmus. Functional bicornuate uterus with cervical atresia combined with vaginal agenesis is a very rare condition. Obstructions of the cervix and vagina prevent menstrual debris from being discharged down and retrograde menstruation resulting in ectopic implantation of endometrial tissue (Sampson theory) (7). These women typically develop severe forms of pelvic endometriosis. Presence of patent fallopian tubes, functioning endometrium and an outflow obstruction is associated with a high (up to 77\%) incidence of endometriosis (8). Goluda M et.al.in 2006 reported a case of bicornuate rudimentary uterine horns with functioning endometrium and complete cervical vaginal agenesis coexisting with ovarian endometriosis (9). She was offered resection of the rudimentary uterine horns with bilateral salpingo--oophorectomy for relief of her severe cyclical pain. Yang C C et.al. in 2002 reported a similar case of uterus didelphys with cervical agenesis associated with adenomyosis, a leiomyoma and a ovarian endometriosis (10). She underwent exploratory laparotomy and total abdominal hysterectomy with bilateral salpingo-oophorectomy. The high morbidity and mortality often associated with endeavours to conserve the reproductive tract in these women have made 
hysterectomy the commonly recommended treatment modality. Treatment modalities in patients with functional uterus and vaginal agenesis that preserve reproductive function are thus controversial. Recently, however, reports have suggested that successful canalization procedures can be safely performed in selected cases of cervico-vaginal abnormalities. The first successful pregnancy after McIndoe vaginoplasty and cervical stenting for partial cervical atresia and vaginal agenesis was reported by Hampton et al in 1990(11). Surgical reconstruction of the atretic cervix may restore fertility and the perception of health, but hysterectomy may remain the definitive therapeutic modality.

CONCLUSION: Cyclic pelvic pain since the age of 14years was due to cryptomenorrhea in the presence of the bicornuate uterine horns with functioning endometrium and cervical-vaginal agenesis. Ovarian endometriosis developed as a result of retrograde spill. In such cases, invasive procedures, such as laparoscopy or laparotomy, should be considered to establish the diagnosis. Removing the functioning rudimentary uterine horns just after menarche should prevent the development of endometriosis and hematometra.

\section{REFERENCES:}

1. Griffin J.E, Edwards C, Madden, J.D et al (1976). Congenital absence of the vagina. The Mayer-Rokitansky-Kuster-Hauser syndrome. Ann. Intern. Med., 85, 224-236.

2. Salvatore C.A. and Lodovicci O (1978).Vaginal agenesis: an analysis of ninety cases. Acta Obstet Gynecol Scand, 57, 89-94.

3. Strassmann EO. Operations for double uterus and endometrial atresia. Clin Obstet Gynecol. $1961 ; 4: 240$.

4. Strassmann EO. Fertility and unification of double uterus. Fertil Steril. Mar-Apr 1966; 17 (2):165-76.

5. Golan A, Langer R, Bukovsky I et al. Congenital anomalies of the mullerian system. Fertil Steril. May 1989; 51(5):747-55.

6. Grimbizis GF, Camus M, Tarlatzis BC et al. Clinical implications of uterine malformations

7. and hysteroscopic treatment results. Hum Reprod Update. Mar-Apr 2001; 7(2):161-74

8. Sampson, J.A. (1927) Peritoneal endometriosis due to menstrual dissemination of endometrial tissue into the peritoneal cavity. Am. J. Obstet. Gynecol., 14, 422-469

9. Mishel DR, Goodwin TM, Brenner PF. Management of common problems in Obstetrics and Gynaecology .4th edition: 2002; 400-405.

10. Goluda M, St Gabrys M, Ujec M et al. Fertile Steril. 2006 Aug; 86(2):462.e9-11. Epub 2006 Jun 27.

11. Yang CC, Tseng JY, Chen P et al. Uterus didelphys with cervical agenesis associated with adenomyosis, a leiomyoma and ovarian endometriosis - a case report. Reprod Med.2002 Nov; 47(11):936-8.

12. Hampton, H.L., Meeks, G.R., Bates, G.W. et al. (1990) Pregnancy after successful vaginoplasty and cervical stenting for partial atresia of the cervix. Obstet. Gynecol., 76,900-901. 


\section{CASE REPORT}

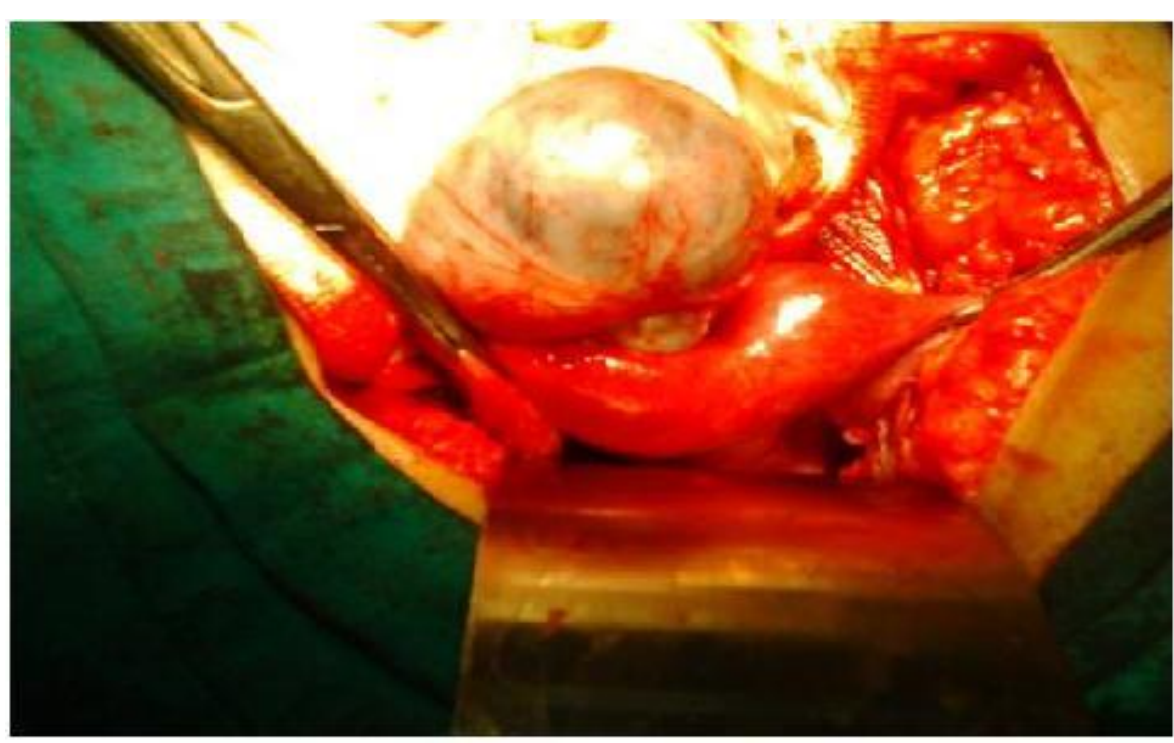

Figure 1 Bicornuate uterus with right chocolate cyst

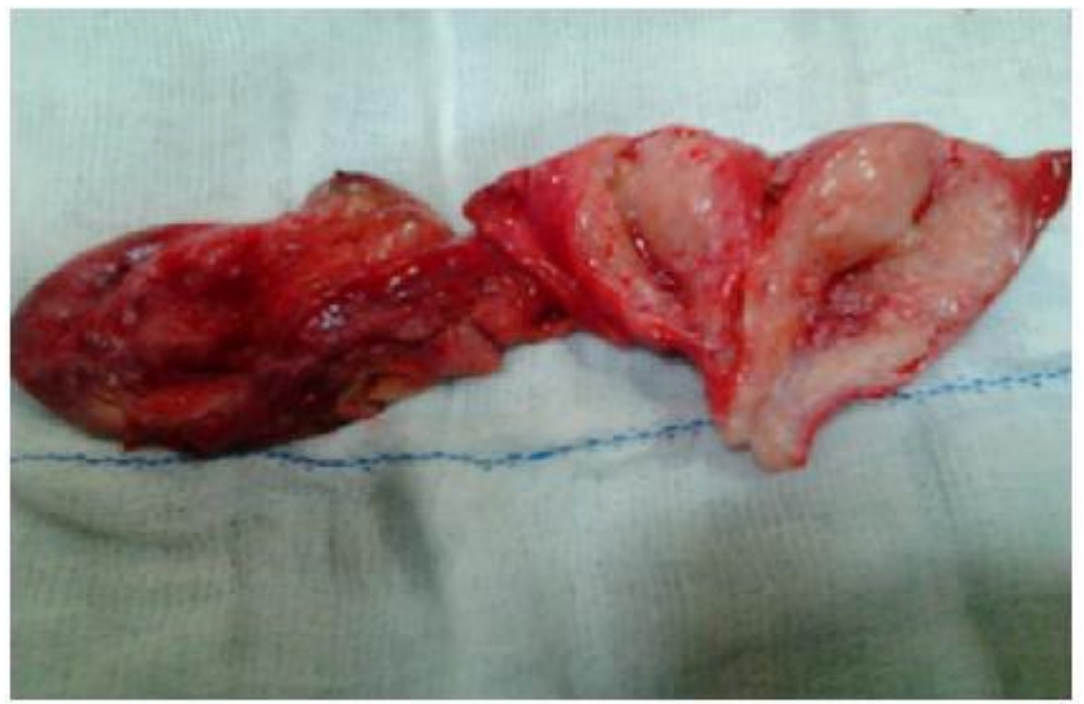

Figure2 Cut section showing two endometrial cavities with noncanalized cervix 